\title{
Civil Society and Interest Groups in Contemporary Japan
}

\section{Author(s): Yutaka Tsujinaka and Robert Pekkanen}

Source: Pacific Affairs, Vol. 80, No. 3 (Fall, 2007), pp. 419-437

Published by: Pacific Affairs, University of British Columbia

Stable URL: http://www.jstor.org/stable/40023391

Accessed: 15-01-2018 07:54 UTC

\section{REFERENCES}

Linked references are available on JSTOR for this article: http://www.jstor.org/stable/40023391?seq=1\&cid=pdf-reference\#references_tab_contents You may need to log in to JSTOR to access the linked references.

JSTOR is a not-for-profit service that helps scholars, researchers, and students discover, use, and build upon a wide range of content in a trusted digital archive. We use information technology and tools to increase productivity and facilitate new forms of scholarship. For more information about JSTOR, please contact support@jstor.org.

Your use of the JSTOR archive indicates your acceptance of the Terms \& Conditions of Use, available at http://about.jstor.org/terms

Pacific Affairs, University of British Columbia is collaborating with JSTOR to digitize, preserve and extend access to Pacific Affairs 


\title{
Civil Society and Interest Groups in Contemporary Japan
}

\author{
Yutaka Tsujinaka and Robert Pekkanen*
}

\begin{abstract}
I ntroduction

In recent years, there has been a veritable explosion of new writings on civil society in Japan. ${ }^{1}$ In some ways, this represents a natural extension of the general rise over the last two decades in interest in the topic among scholars, especially political scientists. In the study of Japan, however, this new vein of literature could force a rethinking of widely accepted views about the nature of Japanese politics, the role of societal actors and their relationship to state power. Accordingly, this article probes the extent to which the new literature on civil society should lead to a revised understanding of Japan's political economy and policymaking processes.

Let us recall the industrial policy and political economy literature (hereafter "political economy literature") that reached its heyday in the 1980s and 1990s and painted a very different picture of Japan. Despite substantial
\end{abstract}

* The authors thank Saadia Pekkanen, Ethan Scheiner, Martha Walsh, the editors and the two anonymous referees for comments on this manuscript. We also thank T.J. Pempel, Susan J. Pharr, Keiichi Tsunekawa, Jaeho Yeom and especially Takafumi Ohtomo for comments on earlier versions. Some of the statistical analyses and results presented in this article appear in a somewhat different version in Yutaka Tsujinaka, ed., Nihon no gendai shimin shakai-rieki shuudan [Japan's Contemporary Civil Society and Interest Groups] (Tokyo: Bokutakusha, 2002), but our argument here is original.

1 Recent examples from these pages include Paul Waley, "Ruining and Restoring Rivers: The State and Civil Society in Japan," Pacific Affairs, vol. 78, no. 2 (2005), pp. 195-216; and Apichai Shipper, "Foreigners and Civil Society in Japan," Pacific Affairs, vol. 79, no. 2 (2006), pp. 269-289. See also Jennifer Chan-Tiberghien, Gender and Human Rights Politics in Japan: Global Norms and Domestic Networks (Stanford: Stanford University Press, 2004); Koichi Hasegawa, Kankyou undou to atarashii koukyoukenkankyou shakaigaku no paasupekuchibu [Environmental Movements and the New Public Sphere: The Perspective of Environmental Sociology] (Tokyo: Yuhikaku, 2003); Frank J. Schwartz and Susan J. Pharr, eds., The State of Civil Society in Japan [Cambridge: Cambridge University Press, 2003]; Susan J. Pharr, "Targeting by an Activist State: Japan as a Civil Society Model," in Schwartz and Pharr, eds., The State of Civil Society in Japan; Robert Pekkanen, "Japan's New Politics: The Case of the NPO Law," Journal of Japanese Studies, vol. 26, no. 1 (2000), pp. 111-148; Robert Pekkanen, "Molding Japan's Civil Society," in Schwartz and Pharr, eds., The State of Civil Society in Japan; Robert Pekkanen, "After the Developmental State in Japan," Journal of East Asian Studies, vol. 4, no. 3 (2004), pp. 363-388; Robert Pekkanen, "Social Capital without Advocacy," in Muthiah Alagappa, ed., Civil Society and Political Change in Asia (Stanford: Stanford University Press, 2004); Robert Pekkanen, Japan's Dual Civil Society: Members without Advocates (Stanford: Stanford University Press, 2006); Stephen P. Osborne, ed., The Nonprofit and Voluntary Sector in Japan (London: Routledge, 2003); Tsujinaka, ed., Nihon no gendai shimin shakairieki shuudan; Yutaka Tsujinaka, "Japan's Civil Society Organizations in Comparative Perspective," in Schwartz and Pharr, eds., The State of Civil Society in Japan; Naoki Tanaka, Shimin shakai no borantia [Volunteers of Civil Society] (Tokyo: Maruzen, 1996); Jeffrey Kingston, Japan's Quiet Transformation: Social Change and Civil Society in the 21st Century (New York: RoutledgeCurzon, 2004). 
differences in the views of the authors, two common threads of much of this literature were the primacy of the economic bureaucracy and a limited set of privileged civil society actors, primarily producers' groups. ${ }^{2}$ Although labour unions were most famously excluded, so were women's organizations, minority groups, many consumer groups, environmental advocacy groups and many others. ${ }^{3}$ In fact, ideas such as "bureaucratic dominance," "patterned pluralism" and "corporatism without labour" are inextricably premised on the exclusion from power of certain political actors. For example, the "pattern" in "patterned pluralism" shows up because some groups are allowed influence and others not. Although authors such as Richard Samuels, Michio Muramatsu and Ellis Krauss, and Chalmers Johnson might disagree on the precise nature of the power relationships among business, bureaucrats and interest groups, the consensus was that economic interests were powerful and represented while others were given short shrift. ${ }^{4}$ Japan was a "producers' society," not a "consumers' society," and almost the only groups that really mattered were economic interest groups.

Yet, at several turns, the civil society literature has urged us to consider a broader range of actors as politically relevant. Jennifer Chan-Tiberghien and Kim Reimann persuasively show how international actors and norms can exercise influence through and on domestic civil society groups. Apichai Shipper examines groups that support foreign labourers and finds that, at least before the state applies itself, they can shape the public sphere. Robert Pekkanen insists that even mundane neighbourhood associations can support policy implementation, among other policy virtues. Jeffrey Kingston, Koichi Hasegawa and Yutaka Tsujinaka recognize the significance of civil society actors. $^{5}$

2 The locus classicus for the developmental state is Chalmers Johnson, MITI and the Japanese Miracle: The Growth of Industrial Policy, 1925-1975 (Stanford: Stanford University Press, 1982). Corporatism in Japan is most famously explored in T.J. Pempel and Keiichi Tsunekawa, "Corporatism without Labor? The Japanese Anomaly," in P. Schmitter and G. Lehmbruch, eds., Trends Towards Corporatist Intermediation (Beverly Hills: Sage, 1979), pp. 231-270. The patterned pluralism citation is Michio Muramatsu and Ellis S. Krauss, "The Conservative Policy Line and the Development of Patterned Pluralism," in Kozo Yamamura and Yasukichi Yasuba, eds., The Political Economy of Japan, Vol. 1: The Domestic Transformation (Stanford: Stanford University Press, 1987), pp. 516-554. See also Richard J. Samuels on "reciprocal consent" in his book, The Business of the Japanese State (Ithaca: Cornell University Press, 1987).

3 On labour, see Pempel and Tsunekawa, “Corporatism without Labor?” For women and minority groups, see Susan J. Pharr, Losing Face: Status Politics in Japan (Berkeley: University of California Press, 1992). For consumer groups, see Patricia Maclachlan, Consumer Politics in Postwar Japan (New York: Columbia University Press, 2002). For minority and environmental groups, see Frank Upham, Law and Social Change in Postwar Japan (Cambridge, MA: Harvard University Press, 1987).

4 Samuels, The Business of the Japanese State; Muramatsu and Krauss, "The Conservative Policy Line"; Johnson, MITI and the Japanese Miracle.

5 Chan-Tiberghien, Gender and Human Rights Politics in Japan; Kim Reimann, "Building Global Civil Society from the Outside In? Japanese International Development NGOs, the State, and International Norms," in Schwartz and Pharr, eds., The State of Civil Society in Japan; Shipper, "Foreigners and Civil Society in Japan"; Pekkanen, "Molding Japan's Civil Society," "Social Capital without Advocacy," 
Although studies of civil society have augmented our comprehension of Japanese politics, observers may be left wondering what is going on. Have traditionally powerful economic interest groups been eclipsed by newer civil society organizations, or simply lost their influence altogether? Conversely, while we know of the rising importance of civil society groups, how do they stack up to the economic interest groups that attracted so much attention in the scholarship of the 1980s and early 1990s? In fact, the relationship between newer civil society organizations, such as citizens' groups (shimin dantai in Japanese), and the older economic interest groups has not been made clear because much of this new literature does not directly speak to earlier analyses of Japanese policy making and polity, which often focused on the role of groups in the making of industrial policy. Studies of civil society seldom challenge earlier understandings of the influence of the bureaucracy, and indeed Robert Pekkanen sees the state and bureaucracy as influential. ${ }^{6}$ By invoking the idea that other actors have influence, however, these studies at least implicitly raise the issue.

Our argument in this article is not that these recent analyses of civil society are incorrect; many are compelling and have enriched our understanding of Japan. Rather, we seek to place these two literatures-the older work on political economy and the more recent writings on civil society-in perspective. Without such a linking perspective, it is difficult to weigh the relative merits of these conceptions. Do the civil society and political economy strands of analysis of Japan differ in emphasis only because of the interest of the authors, or do they disagree about the relative power of these groups? And, how would we compare the importance of new civil society groups with traditional economic groups? Because of the nature of our evidence, we are able in this article to make some systematic comparisons. We hope this will help to connect current research agendas more systematically with welldeveloped earlier themes.

This article has two main goals. First, it provides a macro-level overview that covers both economic interest groups and other civil society organizations. We present a broad picture of the influence of interest groups on public policy and policy making in Japan based on statistical analysis of the Japan Interest Group Survey (JIGS), as detailed in the next section. Such an approach naturally has its strengths and limitations. As we discuss the particular methodology employed, we comment specifically on the limitations to our study. In general, however, a survey can complement more detailed studies of particular policy areas. Moreover, a survey of a very broad range of

and Japan's Dual Civil Society; Kingston, Japan's Quiet Transformation; Hasegawa, Kankyou undou to atarashii koukyouken; Miranda Schreurs, Environmental Politics in Japan, Germany, and the United States (Cambridge: Cambridge University Press, 2002); and Tsujinaka, ed., Nihon no gendai shimin shakai-rieki shuudan. 6 Pekkanen, Japan's Dual Civil Society. 
civil society actors across issues can provide perspective that is not available through case studies-even excellent and thorough ones-limited to a particular issue area or type of group. Our aim in this article is to provide such a comprehensive survey of the involvement of civil society groups in policy making in Japan in order to address the important questions raised above.

As a second goal, in this article we hope to link the literatures on economic interest groups and civil society and in so doing to place the achievements of civil society groups in perspective. Because the comparative analysis we attempt can systematically detect differences across sectors or types of interests by a multisectoral or macro-level overview, our results show that the traditionally powerful economic interest groups are stronger and more influential than the new civil society groups and citizens' groups. We do not seek to demean the real and important achievements of civil society-our objective is not to demonstrate the powerlessness of civil society groups (and thus provide a convenient straw man for future graduate students). Instead, we hope our findings here will compare the accomplishments and influence of economic interest groups with other civil society groups in order to provide a comparative perspective on their respective influence in the Japanese policymaking process. In a systematic analysis of Japan, we find that Japanese associational structure is characterized by the pronounced strength of economic or business organizations compared to other groups. This is true when we look at the number of groups, the size or resources of the organizations and the success that economic groups have in gaining access to policy makers.

In this article, we conceive of economic interest groups as a powerful subset of civil society organizations, and the term "interest groups" here should be seen as differentiating those civil society groups that have direct ties to an economic interest. Specifically, we use "interest groups" to refer to economic interest groups such as industry associations, groups representing a specific profession (e.g., the Japan Medical Association), labour unions and agricultural cooperatives (all these types have separate categories in the survey itself). This distinguishes these groups from a larger set of "civil society organizations," which may advocate for policy change but do not directly represent an economic interest such as that of farmers, workers or automobile manufacturers. Occasionally, in the same sentence we will refer to "interest groups" in contrast to "civil society organizations," in which case the reader should understand the latter as shorthand for "civil society groups other than interest groups."

A more detailed description of our methodology follows this introduction. After this, we plunge into the substantive analysis of the article. We focus on three main aspects. First, we distinguish between the types of groups that involve themselves in policy making. These groups are broken down in the JIGS survey by their predominant activity (e.g., agricultural groups, sports 
groups) and their legal status. Second, we investigate the policy areas that interest the JIGS organizations. We spend the bulk of our efforts, however, in probing how civil society groups seek to influence. This includes detailing the concrete activities and steps taken to influence policy and specifying the political actors targeted for influence. We also include in this category details such as whether the groups offered electoral support or provided postretirement jobs to bureaucrats and whether they focused their efforts on politicians or bureaucrats. In the conclusion, we investigate the success the groups have in gaining access to political actors. We also draw out implications for the study of interest groups and civil society in Japan and for a more general understanding of Japanese politics.

\section{Methodology: A note on the JIGS survey}

The evidence is drawn from the JIGS survey of interest groups conducted by Yutaka Tsujinaka. This extensive survey involved 36 questions and 260 subquestions and utilized random sampling of the Nippon Telephone and Telecommunications Town Page (shokugyoubetsu denwachou), the "NTT telephone book." The directory listed all groups that held a phone line and did not request an unlisted number. Almost every group that held a phone line was listed in the NTT telephone book. Of course, not all groups necessarily have their own telephone lines, but this method of sampling allows the research to include groups that had not obtained legal status or did not even have their own office. In this way, the JIGS data are more comprehensive than government data and catch many groups that would otherwise be uncounted.

The NTT telephone book is a comprehensive listing of telephone numbers and includes the useful category of "unions and associations" in which most organizations that are not corporations list their numbers. There are no significant competing categories that might siphon off portions of the population of organizations and thus create bias in the survey itself. There are also no categories or types of groups that should be systematically underrepresented in the NTT telephone book. In the 1997 editions used for this survey, there were 21,366 organizations listed in Tokyo and 1,762 in Ibaraki Prefecture (a rural and traditionally conservative prefecture north of Tokyo in the Kanto area); these 23,128 organizations were the population of the JIGS survey. School legal persons (private schools), social welfare legal persons and medical legal persons were excluded from the survey (legal personality refers to officially recognized incorporation as a legal entity). Religious groups such as churches and temples were also excluded, although associations that represent religious groups were included, as were religious groups not involved in a religious mission (e.g., YMCA). Cooperatives were included in the survey. As can be seen, groups that fit common definitions of interest groups were all included, and we hope our specificity about the 
data will allow readers with different operating definitions of civil society to still seek insights from this analysis.

The JIGS team employed random sampling and used the postal service to send out questionnaires. Mailed questionnaires hold several advantages. The cost is relatively low compared to other forms of gathering data from organizations. In addition, using such a method allowed us to broaden the sample size far beyond what we could have done with detailed case studies, or even interviews; using these questionnaires, we were able to conduct large$\mathrm{N}$ research. One prime disadvantage to mailing survey questionnaires is that the rate of response can be so low as to call the results into question. However, the JIGS survey enjoyed a very high return rate (40 percent average) and a very high response rate (more than 70 percent). In this survey, the team sent questionnaires to 4,247 organizations (3,866 in Tokyo and 381 in Ibaraki) and had 1,635 returns (1,438 from Tokyo and 197 from Ibaraki). The head of the organization or the person in charge of administrative matters usually answered the questionnaire. The valid return rate was 37.2 percent in Tokyo and 51.7 percent in Ibaraki. We received responses from groups that make up 6.7 percent of all groups listed in the telephone directory in Tokyo and 11.2 percent in Ibaraki. These are quite large samples.

The JIGS survey included questions specifically designed to reveal the policy influence and interests of the target groups. We discuss these results below. Moreover, we can investigate these data along with a fairly detailed profile of the group, including the type of group, its legal status and the size of the group.

Given this methodology, we are confident that the JIGS results are fair and representative of interest groups and civil society groups in Japan-at least as defined by the parameters of the survey. What kind of groups responded to the JIGS survey? In other words, what do we know about the civil society organizations whose influence on policy is the subject of study in this article? We address these questions in the following section. ${ }^{7}$

Surveys similar to JIGS have been conducted in several other countries: Korea, the United States, Germany, China, Russia, Turkey and the Philippines during the 1997-2005 period. For maximum comparability, the surveys are similar in format and methodology to the JIGS survey. Naturally, where necessary the surveys were tailored to local conditions, and response rates and patterns varied across countries. We reference these studies occasionally for illustration, but forgo details in the interest of space and because they are not central to our arguments below.

7 Readers might ask what has happened since the survey was conducted. Without systematic data, we can only speculate or at best construct plausible hypotheses. Fortunately, the JIGS team will conduct a second survey of organizations in the near future to examine changes that have occurred. 


\section{Civil Society and Interest Groups in Contemporary Japan}

\section{Who? What kind of civil society organizations influence policy?}

In this section, we provide an overview of the contours of civil society in Japan. We see that economic interest groups are more prevalent as a proportion of all civil society groups in Japan than in other countries. Moreover, comparing Japanese economic interest groups with other types of civil society groups in Japan, we see that interest groups have vastly greater organizational resources, such as finances and staff. Although this alone is far from conclusive, we take it as evidence consistent with the earlier political economy literature's view of Japan.

\section{Types of Groups}

We present first an overview of the distribution of types of groups to demonstrate the dominance of economic groups, both vis-à-vis other types of groups domestically, and also in comparative perspective. Here, the data are broken down by the predominant activity or area of the groups, as selfreported. In the JIGS survey, organizations were asked to identify themselves in one of 11 classifications created by the survey team: agricultural, business, ${ }^{8}$ labour, educational, administrative, welfare, professional, political, citizens (shimin dantai), religious and other.

Figure 1 reports the distribution of JIGS groups in Japan $^{9}$ and places this breakdown in comparative perspective by providing similar figures for Russia,

Figure 1:

Comparison of Distribution of Groups in Five Countries by Type and \%

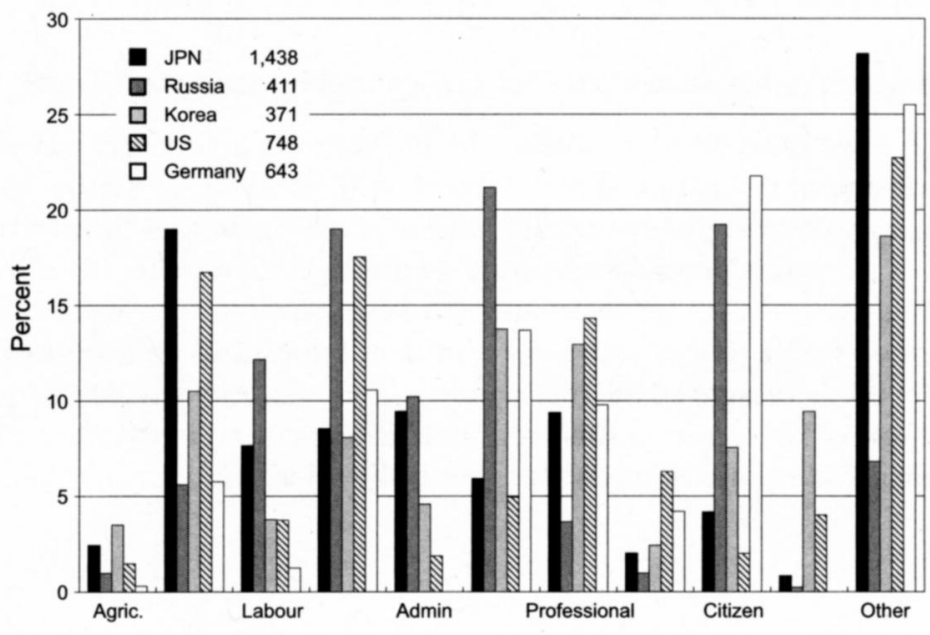

8 This category includes business groups, trade associations, industry associations and the like.

9 For Japan, the reader will note a large "other" section and perhaps wonder if many noneconomic organizations are hidden in that category. Organizations that self-reported "other" in 
Korea, the United States and Germany. The figure shows the preponderance of business organizations in Japan and how the share of business organizations is higher in Japan than elsewhere.

\section{Distribution of Organizational Resources}

An analysis of the distribution of groups is a necessary step to understand the structure of civil society in Japan. However, an analysis of the different resources available to types of groups reveals patterns that cast light on our animating question of the relative power of interest groups and other civil society organizations. Of the 11 types of groups in the JIGS survey, business organizations had far greater access to resources. For example, only 5.1 percent of citizens' groups had budgets greater than US $\$ 1$ million per year, versus 40.9 percent of business organizations. Similarly, 42.7 percent of business organizations had more than five full-time staff members, but only 18.8 percent of citizens' groups did. Citizens' groups are an especially apt category to compare with business groups when we keep in mind the literatures cited above on economic interest groups and civil society organizations. "Citizens' groups" was a self-defined category in the JIGS survey, as indeed it is more generally in contemporary Japan. The category implies the most independent type of civil society organizations, perhaps the closest to what North Americans would consider "real civil society" groups. Resources alone do not necessarily translate into power in all cases. To compare interest groups and civil society groups, however, an important first step is to identify the number of groups and their resources in a directly comparable manner. So far, our evidence is consistent with the political economy view of Japan.

\section{What? In which policy issues are civil society organizations involved?}

Now that we have an idea of who the civil society actors are, we turn to their involvement in a range of issues. We want to determine whether groups care about policy and policy making, and we investigate this "involvement" in terms of (1) self-reported expression of interest in an issue, (2) different activities engaged in on an issue and (3) relationships with various other political actors. The JIGS survey has a number of questions and subquestions that allow us to disaggregate this concept and quantify involvement at a variety of levels. We report in this section on interests and in the next section on activities and relationships with other political actors.

Q1 of the JIGS survey were further asked to specify their type of organization. The breakdown of this "other" category is consistent with the overall JIGS survey. One hundred of the 417 "other" groups chose not to respond, but "commerce and industry" took the plurality (68) of those who did. 


\section{Interest in an Issue}

One fairly low threshold of involvement is whether organizations reported an interest in a particular issue. One survey question at this level of involvement broke down 22 areas of policy and asked: "Among national and local public policies, which policy or activity areas are you interested in?" One of the main findings presented in this article is that nearly all of the organizations responded that they were interested in one of the 22 public policy areas. Recall that the organizations we examined were selected randomly from a telephone directory and that they were by no means necessarily well known. Such a result implies strongly that all of these organizations had an interest in public policy. This important finding further implies that civil society organizations in general have an interest in public policy. Moreover, this helps us to compare interest groups and civil society groups. After all, if certain types of groups were not at all interested in policy, lack of access to policy makers might not be important for them. However, the near-universal interest in policy implies that the vastly differential involvement in policy making that we see in the next section is more consequential.

We also were able to investigate the intersection of group type with interest in particular public policy issue areas. In other words, we can see what kinds of groups are interested in which kinds of policies or which kinds of policies interest which groups. One fairly predictable result of this analysis is that organizations were particularly interested in the public policy issues close to their predominant activity. For example, 97 percent of agricultural organizations wére interested in agricultural policies, nearly all labour organizations (95 percent) were interested in labour policies and welfare organizations (91 percent) were interested in welfare policies.

\section{A Bigger Public for Some Public Policies}

Another less intuitive result is that there are some issue areas in which most groups express an interest. For example, most organizations have policy interests in welfare, environment and finance. A diverse set of organizations showed a high interest in environmental policy (political organizations, 59 percent; citizens' organizations, 57 percent; business organizations, 44 percent; professional organizations, 42 percent; labour organizations, 40 percent; and agricultural organizations, 40 percent). Generally, in Tokyo, many organizations showed interest in new policies related to civic activities such as welfare, environment, education/sports, international and consumers. Next were policies related to the economy and special interests such as industry, finance, money, international trade and industry, regional development, telecommunication and construction. On the other hand, organizations' interests toward traditionally state-related policies such as foreign policy, human rights, security and public safety were relatively low. There was a fairly clear hierarchy of how "general" or widespread was the 
interest piqued by policies. It is tempting to wonder if some policy areas more clearly provide public goods than others, or if they simply affect more constituencies.

\section{Specialist and Generalist Organizations}

Looking at organizations instead of policies, we can classify some organizations as "specialists," because they care only about one type of issue, and others as "generalists," who care about a broad variety of issues. Generalist organizations show interest in more than five policy issue areas. By type of group, they were most prominent among political (69 percent), labour (61 percent) and business (56 percent) organizations. However, 40 percent of citizen, professional, agricultural and educational organizations, and less than 30 percent of administrative and welfare organizations showed interest in more than five policy areas.

\section{Geographic Scale of Activities}

Groups active in some issue areas were more likely to be purely local players, while other policy areas (or types of groups) were active on the national stage. To probe the geographic scale on which groups were active, the JIGS survey broke the geographic scale into local level (shichouson), prefectural level, regional (multiple prefectures), national and international. The scale of an organization's activities seemed to have a relationship to the types of issues the group expressed interest in. For example, groups that claimed operation on an international level expressed interest in international cooperation issues (kokusai kyouryoku) (67.2 percent) and foreign policy (22.9 percent), but groups that operated only on a prefectural level expressed little interest in international cooperation issues (13.7 percent) or foreign policy (5.2 percent). Groups active on the national level were in general not very interested in international issues. For example, foreign policy (7.8 percent) and national security policy (6.5 percent) are among the least popular policy issues among the organizations surveyed, ranking along with legal and human rights policies (7.7 percent).

We also found that groups that operated on different scales relied on different sources of information. For example, local groups relied more on other groups than any other source of information, followed closely by local governments. On the other hand, groups active on an international scale relied on specialists more than any other information source and very little on local governments.

\section{How? What means do civil society organizations use to influence policy?}

Interest is one thing, but taking action is quite another. In this section, we use the JIGS data to investigate the specifics of how civil society organizations act in the policymaking process. We also probe the relationships that the 


\section{Civil Society and Interest Groups in Contemporary Japan}

JIGS groups had with other political actors. Here we are able to compare the access that economic interest groups and noneconomic groups had to policy makers. All told, we find that economic organizations had much more contact with policy makers than did other types of civil society groups. Overall, the policy economy models of the 1980s literature seem surprisingly robust.

\section{Activities on an Issue}

The JIGS survey detailed how groups try to influence policy making. Although interest in policy issues is universal, only about half of the groups were active in lobbying in more than one issue area. The JIGS survey asked about seven types of activities, and if a group reported activity in one of the issue areas, its answer counted as expressing action or activity on that issue. The activities were contacting the ruling party, contacting the opposition party, contacting the central bureaucracy, holding a mass meeting, running an opinion ad in the mass media, holding a press conference and forming an alliance or coalition with other groups. This list does not include all possible forms of political participation (for example, it excludes protests), but it is fairly broad (see table 1 ). Nearly half (43 percent) of all civil society organizations were actively involved in policymaking processes as an interest group or a pressure group. Moreover, 10 to 20 percent of the groups showed active support with a clear political party preference on issues related to election campaign, party contact, policy proposal, budget activities and

Table 1:

Type of Political Activity by Percentage of Groups Engaged in It

\begin{tabular}{lc}
\hline Type of activity & \% of groups engaged \\
\hline Political aim & 56 \\
Public enlightenment & 27 \\
Policy recommendation & 17 \\
Defending rights & 26 \\
Cooperative relationship with the administration & 14 \\
Lobby central bureaucracy through politicians & 31 \\
Lobby local governments through politicians & 27 \\
Lobby local or national government through politicians & 38 \\
Contact ruling party & 16 \\
Contact mass media & 16 \\
Overall lobbying & 43 \\
$\quad$ coalitions with other groups & 8 \\
$\quad$ mass gatherings & 6 \\
paid advertisements & 4 \\
Offer jobs to retiring bureaucrats & 10 \\
Election campaigning & 15 \\
$\quad$ mobilize members for voting & 11 \\
provide staff support for election campaign & 5 \\
\hline
\end{tabular}


advisory council (shingikai) participation. Overall, we find that political and agricultural organizations were the most active in policy making, followed by labour, civic and business organizations. We turn to a more detailed analysis below.

\section{Relationship to Other Political Actors}

Politics involves working with other political actors. The JIGS survey also asked a number of questions designed to measure the relationship between civil society organizations and other political actors, including the central bureaucracy, local government and local and national politicians, of course, but also with other occasional political actors such as academics, mass media, welfare organizations and other civil society organizations. The question posed to the JIGS groups was, "What kind of a relationship does this organization have to yours? Please answer on a 7 point scale from 'highly oppositional' to 'very cooperative." An entity that every JIGS group reported as having a very cooperative relationship to its own scored a perfect 7 , and conversely an entity reported as oppositional to all JIGS groups scored a 1. More generally, scores over 4 meant that entities' relationships with the JIGS groups were more cooperative than adversarial. We review these figures only for groups active at the national level. The only type of group to score under 4 was foreign interest groups. On the other hand, the entity reported as having the most cooperative relationship with the JIGS groups was the central bureaucracy (4.67), followed by academics (4.54), local governments (4.48), mass media (4.44), welfare organizations (4.39), political parties (4.35) and big business (4.29). However, the standard deviation for the bureaucracy was higher than for any other entity (1.19); thus, we need to look at the relationship between the bureaucracy and other individual organizations separately. The organizations most cooperative with the bureaucracy considered themselves administrative organizations (5.15), and next were business organizations (4.91) and agricultural organizations (4.86), followed by professional organizations (4.68) and groups involved in welfare (4.63) and education. Groups that identified themselves as citizens' groups were much less likely (4.08) to consider their relationship with the bureaucracy as cooperative, followed by political organizations (4.00), which were neutral, and labour organizations, which were the only groups to view the bureaucracy antagonistically (3.36).

\section{Bureaucrats the Favourite Target for Lobbying}

The introduction pointed out that bureaucratic power was a staple of the earlier political economy literature. Like the new civil society literature, this article is less concerned with investigating that tenet than in the primacy of economic interests. However, we do find some evidence for the continued importance of bureaucrats. The JIGS survey lets us examine the group 


\section{Civil Society and Interest Groups in Contemporary Japan}

(bureaucracy, political party or courts) targeted by organizations active in various geographical areas to press their claims. AJIGS question asked, "When you try to make your organization's opinion heard or defend the interest of your organization, which one of the three (bureaucracy, political party and courts) do you think is most effective to contact?" We broke the responses to this question down by the scale of activity for the organizations (local to international). At every level, the bureaucracy was targeted as the most effective to contact by a substantial margin, followed by political parties and the courts. This also provides support for the political economy view.

A closer look reveals a few patterns within those broad trends. For example, organizations active regionally tended to choose political parties more than those with different scopes of activity. Organizations active at city/town/ village levels and regional areas targeted the courts more than other organizations. The gap between the administration and political parties becomes the smallest for organizations that operate regionally. The reason organizations covering regional areas did not choose the administration is perhaps because there is no institution to cover such an unconventional area-Japan has no regional governments.

\section{Who Meets Whom?}

We also examined in greater detail the relationship the JIGS organizations had with state administrative organizations at the national and local levels. When JIGS organizations and the administration engaged in interaction, who met whom? The survey asked, "When your organization directly contacts the bureaucracy, whom (rank) do you meet?" For contacting the national bureaucracy, we provided four levels to choose from: minister/bureau director, chief, chief clerk and rank and file. Choices at the local level were head, chief, chief clerk and rank and file. If at least one of the positions out of four were chosen, we considered that the organization had contact with the bureaucracy. ${ }^{10}$ These are the results reported as the first question in table 2 .

The survey also asked a series of questions regarding the relationships of the JIGS groups with the state administrative organizations and with local government. The questions are summarized in table 2, along with the percentage of JIGS groups that reported such a relationship at either the national or local level. For example, although the first question asked JIGS groups to report interaction with the government at either the local or national level, 72.6 percent of groups had some interaction at one level or the other. We explore these patterns in more detail shortly. What stands out

10 The original question asked the frequency of contact, but here we do not break down by frequency. Organizations can be divided into those that had contact and those that did not. Even organizations that did not have much contact are considered as "having contact." 
Pacific Affairs: Volume 80, No. 3 - Fall 2007

Table 2:

Relationship of JIGS Organizations to National and Local Bureaucracy

\begin{tabular}{|c|c|c|}
\hline Question & $\begin{array}{c}\text { "Yes" at } \\
\text { national level }\end{array}$ & $\begin{array}{c}\text { "Yes" at } \\
\text { local level }\end{array}$ \\
\hline Do you have some interaction with the government? & 58.4 & 46.3 \\
\hline Does the bureaucracy have permitting authority? & 37.3 & 21.6 \\
\hline Does it regulate your activities? & 32.6 & 18.6 \\
\hline $\begin{array}{l}\text { Does it give your organization administrative } \\
\text { guidance? }\end{array}$ & 44.5 & 25.7 \\
\hline $\begin{array}{l}\text { Do you support and cooperate in the policymaking } \\
\text { and budgetmaking processes? }\end{array}$ & 13.9 & 9.7 \\
\hline $\begin{array}{l}\text { Do you exchange information regarding } \\
\text { organization and industries? }\end{array}$ & 35.0 & 23.4 \\
\hline $\begin{array}{l}\text { Do you send your organization members to } \\
\text { advisory committees? }\end{array}$ & 13.0 & 9.0 \\
\hline Do you offer jobs to retired bureaucrats? & 8.4 & 2.9 \\
\hline Do you receive grants or subsidies? & 13.5 & 10.8 \\
\hline
\end{tabular}

is the fairly high percentage of groups that reported receiving administrative guidance (44.5 percent). This figure is higher than the number of groups that reported their activities were regulated by the bureaucracy. Of course, groups' perception of this regulation could vary, but their ability to discern, and therefore report, administrative guidance was likely very high. In addition, the JIGS organizations probably reported quite accurately on topics such as sending their members to advisory committees, offering jobs to retired bureaucrats and receiving grants or subsidies. For these national figures, it is interesting to note that the ratio of groups offering jobs to bureaucrats to groups getting subsidies is about 1:2.

\section{National and Local Contact Patterns}

Some organizations had stronger relationships or more frequent interaction with either local government or the national government. In fact, our analysis reveals four contact patterns: (1) contact both the central government and local government, (2) contact only the central government, (3) contact only the local government and (4) contact neither. Contact patterns differed greatly according to area of activity. Organizations active in city/town/village and in prefectural levels tended to contact local governments only, while national-level organizations contacted the state only. Many organizations active on the regional and international levels tended to contact both the national state and local governments. This may be due to the fact that activity areas and (administrative) regions do not match. Less than 30 percent of organizations did not contact either level of government, local or central. 


\section{Direct and Indirect Contact}

Organizations contacted the administration not only directly but also indirectly. In order to grasp how organizations contacted the administration indirectly, we asked, "Whom do you ask to contact the administration?" The choices are (1) Diet members from the local district, (2) Diet members not from the local district and (3) chief of the municipality and local assembly persons. To contact local government, the choices were (1) Diet members, (2) prefectural or city assembly persons and (3) powerful people in the area. ${ }^{11}$ In general, the most popular answer for indirect contact was "Diet members not from the local district." However, 24 percent of respondents chose this answer, a much smaller percentage than those relying on "direct contact." Organizations active at prefectural and regional levels contacted local Diet members, while those active at regional and national levels contacted Diet members not from the district. Organizations active on the regional level also contacted chiefs and local representatives. These results show that in order to influence Diet members, the area of activity needed to be large. Moreover, those that had indirect contact with political parties tended to use politicians (Diet members, local representatives, chiefs). Some organizations attempted direct contact with the administration but also asked politicians to contact the administration. The percentage of indirect contact with local governments through politicians (11 to 23 percent) was not as large as direct contact (46.3 percent). Organizations active at prefectural and city/town/village levels tended to contact local representatives.

The JIGS survey also asked about consultations regarding policy between the government and the JIGS organizations: "Do national and local administrative organizations contact your organization to ask for advice concerning the making and enforcement of a particular policy? If so, please list all the organizations that contacted you." Among organizations active at the national level (690), 240 (34.8 percent) wrote names of specific organizations that contacted them. Moreover, of those 240 organizations, 62 (25.9 percent) listed more than one organization (maximum 5). ${ }^{12}$

Richard Samuels and others who emphasized the close communication between business and government would not be surprised by the results: we see that the dominant pattern of civil society-state contact is that between business and the economic bureaucracy. ${ }^{13}$ In fact, consultations (45 between

11 Again, the original question asked the frequency of contact. Organizations that did not have much contact are considered as "having contact."

12 If an organization answered several related organizations of the same ministry, we did not consider that the organization had close relations with multiple administrative organizations. Because the survey was conducted by free reply model by mail, there were some inconsistencies with the replies. Some were too general but others were very detailed with specific names. Hence, the measurement of this reply cannot be as rigorous as some other responses.

13 Samuels, The Business of the Japanese State. 
the Ministry of Economy, Trade and Industry [METI] and economic, business or trade organizations alone) between economic organizations and economic ministries number three times more than all consultations of any ministry to citizens' groups, political groups and welfare groups combined (14). Moreover, the economic ministries, in particular METI, engaged in contact more frequently than other ministries. They made 83 consultations, versus only one for the Defense Agency, four for the Environmental Agency and 14 for the Ministry of Labour. Similarly, economic organizations engaged in the most consultations. They engaged in 97 consultations with 17 ministries or agencies. We see here the clear dominance of economics in interactions between JIGS organizations and the government.

Another result that stands out is the emergence of "specialists" and "generalists." Educational groups, for example, are specialists. They engaged in 28 consultations, but most were with the Ministry of Education (86.4 percent), and only with the Ministry of Education did they engage in consultation more than once. Other specialists are agricultural organizations, which have close relationships with the Ministry of Forestry and Fishery and its related organizations. Almost all consultations between agricultural organizations and government involved the Ministry of Forestry and Fishery (91.7 percent). Similarly, economic organizations tended to be involved with METI (68.2 percent of contacts) and welfare organizations with the Ministry of Welfare and its related organizations (66.7 percent). On the other hand, citizens' groups engaged six times in consultations with separate ministries or agencies. They are "generalists," and lonely ones at that.

Business groups had more contact with bureaucrats for two reasons. First, they tended to be larger than other types of organizations, especially when compared with citizens' groups. And, larger groups tended to have greater access to policy makers in general, for the obvious reason that they were more readily seen as influential and important. For example, regardless of the type of group, groups with 30-49 employees were about 10 times as likely to report regular meetings with top bureaucrats (kyokuchou level and above) as groups with fewer than 10 employees. More resources did translate into more access. Second, even controlling for resources, business groups were relatively advantaged. For example, business groups with 30 to 49 employees were almost six times more likely than the average to report frequent meetings with top bureaucrats.

The bureaucracy, of course, is not the only political actor to lobby in Japan. Although many JIGS organizations worked with the local and national bureaucracies, relatively few chose to contact political parties. Figure 2 depicts the pattern in which some groups oriented toward political parties while others worked closely with the bureaucracy. Most organizations interacted only with the bureaucracy (38.2 percent), while almost none chose to work only with political parties (5.4 percent). Of course, many groups contacted the bureaucracy and political parties (34.4 percent). However, this finding 
Figure 2:

Interactions of J-JIGS Organizations with Political Actors

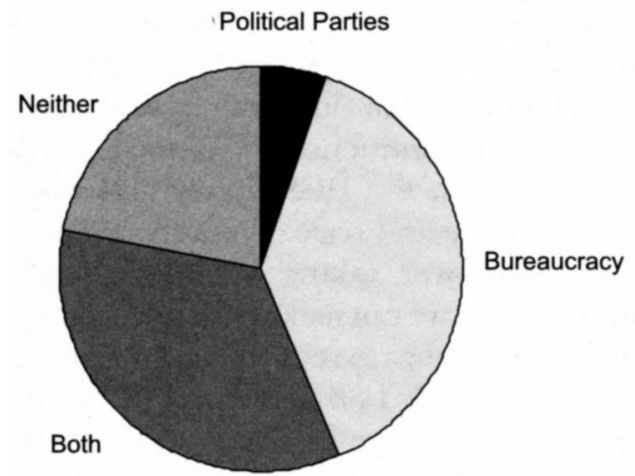

underscores the centrality of the bureaucracy to the lives of JIGS organizations and to the policymaking process in general. To some extent, this finding can also be interpreted as providing evidence for the older political economy literature that stressed the importance of bureaucrats in policy making. ${ }^{14}$

The JIGS survey also asked groups about their sources of information. Examining data only for groups that operate on a national level, we asked groups to rank from 1 to 12 the most important sources of information for their organization from a list: national bureaucracy, group members, other groups, specialist publication, the mass media, scholars, corporations, local government, local politicians, national politicians, political parties and other sources. The results indicate again the tight connections between business organizations and the government. Business organizations rated the national bureaucracy as their most important source of information. By contrast, for citizens' groups, the national bureaucracy ranked fifth, and the mass media ranked at the top of the list. In this respect, at least, there appeared to be a closer relationship between business and bureaucracy, with citizens' groups on the outside, looking in.

\section{Conclusion}

We have discussed the wide range of policy interests of JIGS organizations and examined in some detail their activities and efforts toward influencing the policymaking process. How successful have those efforts been? Stated more broadly, how much do interest groups or civil society organizations influence the policymaking process in Japan?

14 See, for example, Johnson, MITI and the Japanese Miracle. 
We begin with some caveats and revisit our discussion of the strengths and weaknesses of the JIGS survey. The JIGS survey is not an ideal instrument through which to measure policy change. It measures and reports the perceptions of the organizations, not policy change per se. It also relies on how organizations view the policymaking process, rather than examining through process tracing what happens. In this sense, case studies are superior to the JIGS survey in evaluating the influence of civil society organizations on policy making in Japan. However, the JIGS survey also has some concomitant advantages due to its scope and scale. It covers a wide range of issue areas and organizations. Moreover, taking advantage of the surveys in other countries mentioned above, we can make tentative cross-national comparisons.

The JIGS survey asked groups to report on achieving success in influencing (or changing) policy, but only 14.3 percent of JIGS organizations reported such success. This was lower than in Korea, less than half of what German organizations reported (32.5 percent) in the German version of the JIGS survey and a third of what Russian organizations reported ( 46.5 percent) in the Russian version. Japanese groups also reported little success ( 6.5 percent) in blocking policies. Again, this was less than Korean groups (11.1 percent) and much less than the Russian (21.2 percent) and German groups (26.3 percent). At least in terms of groups' perception of their own success, Japanese groups did not have much influence over policy making in absolute or comparative terms.

Another question in the JIGS survey asked organizations to evaluate other actors' influence over policy: "How much influence do groups listed below have on Japanese politics? Please rate from the scale of 1 to 7 ( 7 being the strongest)." Although this necessarily relies on perceptions rather than an "objective" measure of real influence, these groups are often intimately involved in the policymaking process and have a good sense of where the real power and influence lie. In a sense, too, this replicates interviews done in case studies in which researchers ask about who has influence, but it provides insight on a much broader scale. We are able to rank which groups JIGS organizations felt were the most powerful in Japan. We also are able to compare these rankings with similar ones from the JIGS surveys in Korea, Germany and the United States.

The central bureaucracy was perceived as the most powerful entity in Japan, with an average score of 6.32 out of 7 . Again, this is less central to the civil society literature's implied critique of the political economy literature but worth raising nonetheless. The bureaucracy's only real rivals were political parties (6.12). Women's groups were perceived as weakest (3.42), barely exceeded by the category of "nongovernmental [NGO] citizens' groups/ residents' movement groups" (3.48) and welfare groups (3.49). Foreign governments were seen as powerful (5.18), nearly the level of some significant domestic players such as agricultural groups (5.22), the mass media (5.32), big corporations (5.38) and economic groups and managers (5.65). 


\section{Civil Society and Interest Groups in Contemporary Japan}

These rankings are interesting because they reflect the JIGS organizations' view of the world. However, they are also interesting in comparative perspective. Compared to the other three countries mentioned above, bureaucracy, agricultural organizations, foreign governments, international organizations and foreign interest groups were ranked much higher in Japan. Local government was ranked slightly higher or about the same in all four countries. Mass media, labour organizations, consumer groups, NGOs, civil organizations and citizens' movement organizations were ranked lower in Japan compared to the other three countries. Women's organizations and academics ranked slightly lower or about the same. Political parties, economic and business organizations, big firms and social welfare organizations in Japan were ranked at a similar position as in the other countries.

This article has explored the interests, activities and success of interest groups and civil society organizations in influencing public policy making in Japan. Our goal is to place our findings in the context of systematic comparisons with noneconomic organizations and noneconomic ministries. The primary tool has been the quantitative data from the JIGS data. We found that compared to citizens' groups, the type of group most emblematic of "civil society," business organizations have much greater resources and access to policy making. Our evidence reinforces the picture of high levels of communication and interaction between business organizations and the economic bureaucracy. Recall, for example, that consultations between METI and economic, business or trade organizations were three times more than the sum of all consultations between all ministries and all citizens' groups, political groups and welfare groups. Our second main finding uncovered evidence that the bureaucracy remains a powerful actor in Japanese politics, at least according to the perception of civil society actors. The bureaucracy is also central in structuring the political relationships of civil society organizations. Although both our findings seem to support the analyses of the political economy literature, we repeat that we do not see civil society organizations as powerless or insignificant in Japanese politics. Rather, we focus on placing the aggregate strengths, contributions and influence of all sectors of civil society organizations in perspective.

University of Tsukuba and University of Washington, July 2007 